\title{
Cultural Differences and Cultivation of Cross-cultural Communicative Competence in Chinese FLT
}

\author{
Xiaobo Dong \\ School of Foreign Languages and Cultures, Nanjing Normal University \\ Nanjing 210097, China \\ Tel: 86-25-8528-2055 E-mail: dongxiaobo@163.com
}

\begin{abstract}
In order to improve their abilities in cross-cultural communication, language learners should develop not only their language competence, but also communicative competence. This paper presents an understanding on the general cultural differences between the west and China by applying the cultural dimensions of Hofstede and Bond, and points out that the success of cross-cultural communication depends on the competence of cross-cultural communication and gives some suggestions concerning the goals of foreign culture acquisition and the ways of culture training.
\end{abstract}

Keywords: Cultural differences, Cross-cultural communication, Cultivating suggestions

\section{Cultural differences}

What is culture? Among researchers who have given a variety of definitions of culture, As is pointed out by G.Hofstede that culture is a kind of "collective programming of the mind, which distinguishes the members of one category of people from another" ${ }^{\prime \prime}$.With the globalization of world business, the problem of cross-cultural communication arises gradually seriously between China and its culturally different Western partners continues to increase at an unprecedented rate. Hofstede explained that culturally-based values systems comprised four dimensions: power distance, individualism/ collectivism, masculinity/femininity, and uncertainty avoidance. Further research by Michael Bond ${ }^{2}$ identified a fifth "Eastern" dimension called long-term/short-term. By applying Hofstede's and Bond's cultural dimensions, a cultural comparison between America and China is made.

Insert Table 1 and Table 2 Here

In general, China stresses the social role of the group, whereas Western people emphasize individuality. Collectivism is believed to generate more submissive behavior among Chinese in group interaction processes. Specifically, the collectivist concern of Chinese to avoid interpersonal disharmony becomes salient, and this concern can consequently encourage an Chinese group member to avoid open disagreements with other group members and shift toward the majority position more often than Westerners do. Compared with their Western counterparts, Chinese are more situation-centered and are more externally oriented. Chinese people believes in "yuan", which derives from Buddhism and is often used by Chinese as an explanation for personal outcome by alluding to fate. Westerns admire the self-made person----the one who, with neither money nor family influence, fights his or her way to the top. Chinese culture stresses the importance of maintaining harmonious interpersonal relationships and acting in a manner appropriate to one's position in a hierarchical social situation. Therefore in group interaction processes, they are inclined to be more restrained, cautious, patient, and self-contained, and less impulsive, excitable, spontaneous, and natural than Westerns

\section{The Importance of Cultivating Cultural Creativity in FLT}

The teaching of a foreign language inevitably involves the teaching of foreign cultures. We all know that language is a tool for people to communicate with each other. It consists of documents, articles and words people often write. And culture is often referred to the country, the language, the people, the religion, the political institutions, the economy, the social welfare, the mass media, the social behaviors and attitudes and so on. Therefore, language is a part of culture and a means of the culture transmission at the same time, language is influenced by culture and influences culture itself, too.

English, as a foreign language in China, should be regarded not only as a resource for learning foreign cultures but also as a means of cultural interaction. In fact, it necessitates cultural interaction. But in the past, the overemphasis on language structure treats English as a set of abstract linguistic rules, an empty code system or a culturally neutral instrument. However, by focusing on the teaching of language structure, we may not establish a foundation for developing learners' capability for interaction, given that a good understanding of both home culture and foreign culture is the basis for interaction. Therefore, the study of culture, to some extent, may lead to liberation of the mind, to greater international understanding and cooperation, and an acceptance of other people's ways and values. Nevertheless, it is 
too simplistic to think that the study of foreign culture will automatically lead foreign language learners to develop creative power and capacity for change. In other words, the learners may gain cultural knowledge through cultural studies, but this does not guarantee an understanding of the target culture and change of attitude. As Corson (1989) stated,

It is a mistake to equate a growth of "knowledge and awareness of the differences that exist between cultures" with a growth of empathy and understanding. Knowledge and awareness provide little more than the building blocks upon which attitudes can be erected: individuals can hold undesirable and intolerant attitudes, while still being knowledgeable and aware.

In attempting to solve this problem, we suggest that we should focus on developing Chinese students' cultural creativity in FLT, Cultural creativity refers to "a capability which is to be achieved through acquiring knowledge about foreign culture, embedded in language and beyond language, through using this knowledge in the performance of inter-cultural communication and creating new thinking for a new action" (Chen, 1986). Cultural creativity is a kind of creative power to be obtained through language and culture learning. We use "creativity", rather than "capacity" here, for the notion of cultural creativity pays more attention to the students' capability to take part in cultural interaction rather than his/her ability to use a language. To develop students' cultural creativity, first of all, we should consider how to help the Chinese student gain knowledge and raise their cultural awareness. When a person knows little about foreign people and countries, they assume that the ways of life of people in foreign countries are exactly the same as those at home.

As a result, they use their own norms of behavior to interpret foreign people's thinking, behavior and even appearance. So Chinese students should be exposed to sufficient information about foreign culture and then they can turn external knowledge into their own internal knowledge. Secondly, Chinese students should understand foreign culture and their home culture on the basis of previous experience and new knowledge. Finally, from knowledge to understanding, Chinese students should be encouraged to develop an independent ability to perceive "their previous perceptions" so that they establish a dialectical relation with reality.

\section{Approaches to Cross-cultural Awareness FLT}

Cross-cultural awareness acquisition is one of the major goals of foreign language teaching. Cultural awareness is the term used to describe sensitivity to the impact of culturally induced behavior on language use and communication. In order to improve students' consciousness on intercultural communication and cultivate their socio-cultural abilities, the best way is to immerse them in the English cultural atmosphere and make contact with native speakers in person. For doing this, we cannot only get some rational knowledge on their culture, but also learn their culture through the perceptual comparison between their culture and ours. Some approaches are recommended here to help English-learners better perceive and understand cross-cultural awareness:

\subsection{Creating western cultural atmosphere}

We can create Western cultural atmosphere, make ourselves plunged in the atmosphere and learn to speak proper language in different situations. On the cultural atmosphere's creation, we can achieve this by watching movies or by cultural performance. It is an effective method for us to improve our socio-cultural abilities through cultural performance. For example, we can imitate the situation in daily life, such as greetings, chats, reserving by telephone, sending a birthday present, etc. We play the roles and realize the cultural differences, and then we can enhance our understanding and endurance on their culture.

\subsection{Making Chinese Students Learn some original textbooks}

For many years, our textbooks, especially some primary textbooks have put much emphasis on linguistic style while neglect their social meanings and using in real situation. We can see such dialogues in many textbooks:

-What's your name? -My name is... .

-How old are you? -I'm ....

-Where are you from? -I am from... .

These dialogues are made up of "Chinese idea + English style", they all ignore whether it is appropriate to say so. In Western countries, except hospitals or police station, nobody would ask questions like this. On the principle "use what we've learned", we often break westerners' cultural rules, but in the original books, there are no such problems. Thus, we have to learn from the original books and understand more about their culture and customs.

\subsection{Cultivating Students' Intercultural Awareness by reading Literature widely}

Many people think that reading comprehension is a process of understanding words, sentences, and then translating them into our native language. In fact, reading is a complicated thinking process, it's a process in which one's language knowledge, cultural knowledge and other specialized knowledge are affected together, and also it's a process of guessing and correcting our thoughts by using this knowledge. It is generally accepted that literature is a reflection of 
society's view, values and beliefs: a reflection of the social, political, cultural development of any society. It reveals people's ideas and dreams in the most creative and imaginative way. Literary works live in time---in the past, at the present, in the future; there is also a certain continuity of time. This continuity can be interpreted in the following way: in the literature of the past we can find the roots of the present; in the literature of the future we believe we'll see the traditions of the past. Therefore, Literature texts are suitable for developing intercultural communicative competence. Not only do they invite their readers to view subjectively a nation or an ethnic group by portraying specific values, prejudices and stereotypes, but they also offer their audience the chance to xchange their culturally restricted points of view together with the hero or heroine of the narrative, or with the narrator telling his story. Literature texts guide their readers through the reading process focusing their attention not only on actions and characters (Rosenblatt 1982; Bredella, 1996). The 'efferent reading' of texts, a special way of reading fictional texts 'aesthetically' (Rosenblatt,1981; Bredella, 1996), enables and strengthens the readers' interaction with the text, their predicting abilities, their emotional responses as well as their forming and re-forming of hypotheses during the reading process, all of which are necessary to fill the text with meaning.

\subsection{Making Chinese students seek every opportunity to speak with foreign teachers}

Needless to say, foreign teachers who are authentic culture carriers of their native countries are ideal narrators of their own culture. Most of us are sure that we can learn more about cultural background knowledge of the English-speaking countries from our foreign teachers. We can hear our foreigners' personal and oral explanation about their own culture from daily contact with them face to face, and observe and sense the shades of differences between Western and Chinese cultures through their actions and responses to the existing culture.

\subsection{Making Chinese students learn from English teachers actively}

In English study, our English teacher plays the role as a bridge and an explainer. He is very familiar with our Chinese culture and Western culture and can help us avoid using our cultural standards to judge Western culture, and then helps us build up intercultural consciousness as soon as possible. For example, he will explain to us words having cultural meanings, such as fireplace, pudding, sandwich, etc. These things belong to Western culture and can hardly be seen in China, but with the teacher's help we can get their meaning fast and understand them better.

\subsection{Goals of foreign culture acquisition and cultural testing}

In FLT, two languages and indeed, two cultures come into contact because the native speaker of any language has built into his language repertoire his unique cultural assumptions and values. As cross-cultural communication competence has included socio-cultural ability, foreign culture acquisition should be incorporated into EFL acquisition. Based on the works of some experts and linguists (Hu, 1988, Porter and Samovar, 1985), the author suggests the following goals of foreign culture acquisition in EFL teaching and learning in China.

1) To familiarize EFL students with the mundane situations of the English speaking countries - their customs and habits, life-styles, generally-accepted world outlook, etc. It is in the most mundane situations where we find the most obvious cultural differences. Students' attention must be drawn to cultural stereotypes - generalizations which surely help the EFL students to understand some aspects of the foreign culture, but they inherently involve overgeneralization which may block understanding diversities within the foreign culture.

2) To enable EFL students to understand the interaction between language and such social variables as age, sex, race, social classes and occupation, which affect the way people speak and behave.

3) To promote EFL students' cross-cultural awareness and help them know the similarities and differences between Chinese culture and western culture.

4) To enable EFL students to know about history, social and economic circumstances, literature, geography from culture other than their own. These kinds of knowledge can facilitate cross-cultural understanding.

5) To cultivate EFL students' ability to evaluate the culture of the target country in an objective manner. Two extremes - resistance to and the blind worship of western culture - must be avoided. Teachers should enable EFL students to understand and appreciate cultural diversity without losing sight of their national identity or their native cultural norms and values, and to understand the values of ideas from a multicultural perspective knowledge base.

Cultural testing, the last step but not the least, is an indispensable part of a language program. In the sense of intercultural awareness training and intercultural competence development, tests offer opportunities to evaluate this component of the whole curriculum. When designing their tests, teachers of different courses can adopt different test types and should make them properly culture loaded. Teachers of culture courses should especially pay attention to the reliability, validity and practicality of their course evaluation. They should be flexible in designing their test. Role-plays, individual or group presentations, performance shows, etc. should be on their test list. 


\section{Conclusion}

On the whole, the relation between language and culture determines the importance of culture teaching. Especially in ELT, it is necessary and urgent to teach not only cultural knowledge information but cultural communication information as well. Briefly, Culture is an indispensable ingredient of communication and cultural competence --- the mastering of the shared knowledge, assumptions and values of the culture, is one part of communication competence, of which cross-cultural communication competence is a further development, including non-linguistic competence, macro-linguistic competence and communicative competence. Only those competent in the message sender's culture as well as the message receiver's culture can succeed in cross-cultural communication.

\section{References}

Crystal, D. (1997). A Dictionary of Linguistics and Phonetics. Oxford: Blackwell publisher Ltd.

Guixia Sun. (1997). Instructing Foreign Language Teaching from Social Linguistic Aspects. Foreign Language Teaching and Research. Qinghua University Press.

Hofstede G.. (1980). Culture's consequences: International differences in work-related values. Beverly Hills, CA: Sage. Samovar, L. A. \& Porter, R. E. Intercultural Communication: A Reader. Belmont California: Wadsworth Publishing Wenzhong Hu. (1989). English Teaching and Learning. Foreign Language Teaching and Research Press.

Yuhui Yang. (1997). The Influence of Cultural Elements in English Teaching. Foreign Language Teaching and Research. Qinghua University Press.

Table 1. Cultural Dimension Scores of United States and China

$$
\begin{aligned}
& \text { Legend for Chart: } \\
& \text { B - Cultural Dimension Scores Power Distance } \\
& \text { C - Individualism } \\
& \text { D - Masculinity } \\
& \text { E - Uncertainty Avoidance } \\
& \text { F - Long-term Orientation }
\end{aligned}
$$

$\begin{array}{cccccc}\text { A } & \text { B } & \text { C } & \text { D } & \text { E } & \text { F } \\ \text { United States } & 40 & 91 & 62 & 46 & 29 \\ \text { China } & 80 & 20 & 50 & 60 & 118\end{array}$

Table 2. Cultural Differences between America and China

$$
\begin{aligned}
& \text { Legend for Chart: } \\
& \text { A - Cultural Dimensions } \\
& \text { B - USA } \\
& \text { C - China }
\end{aligned}
$$

A

B

C

Individualism/Collectivism Strong individualism Strong Collectivism

Power Distance Medium Centralized, tendency toward democracy

Uncertainty Avoidance Risk-taking Risk-avoiding

Masculinity/Femininity Medium Masculinity Medium Femininity

Long/short-term Orientation

Short-term Orientation

Long-term Orientation 